\title{
Growth and development in premature twins
}

\author{
R MORLEY, T J COLE, R POWELL, ${ }^{*}$ AND A LUCAS \\ MRC Dunn Nutrition Unit and University Department of Paediatrics, Cambridge and ${ }^{*}$ The Ryegate Centre, \\ Sheffield
}

SUMmARY A total of 476 infants (386 singletons and 90 twins) born before 32 weeks' gestation were studied to compare long term growth and development in twins and singletons. At 18 months, after adjusting for confounding social, obstetric, and neonatal factors, twins were not disadvantaged in their neurodevelopmental status, but were $1.6 \mathrm{~cm}$ shorter than singletons and had thicker triceps and subscapular skinfolds. No significant differences were found between first and second born twins in later growth or development at 18 months post-term. While preterm twins may have an inherent disadvantage in linear growth it is suggested that in other respects twinning is not a risk factor in preterm infants.

There is considerable evidence that twins are disadvantaged in terms of perinatal mortality, ${ }^{1}$ long term growth, ${ }^{2-4}$ and neurodevelopmental status. ${ }^{34}$ This may reflect the increased risk of antenatal complications, preterm delivery, and low birth weight in twin pregnancies. ${ }^{5}$ Fifty per cent of all twins are of low birth weight, compared with $6 \%$ of singletons, ${ }^{2}$ and twins account for about $20 \%$ of infants under 32 weeks' gestation (see below). In view of this high frequency of twins within the population of premature babies, and the lack of available data, we considered it important to identify whether twinning was a 'risk factor' for an adverse outcome in infants born preterm. In a study on a cohort of surviving infants born before 32 weeks' gestation we have examined obstetric and neonatal course together with development and growth performance at 18 months post-term. By adjusting for the social, obstetric, and neonatal differences between preterm twins and singletons, we have investigated whether outcome at 18 months differs between the two groups. Furthermore, we considered that our data might throw light on the more general question of whether there is an inherent disadvantage in being a twin or whether the poorer prognosis reported in twins might be related principally to the increased incidence of preterm delivery.

\section{Subjects and methods}

Infants born before 32 weeks' gestation from five centres (Cambridge, Ipswich, Kings Lynn, Norwich, and Sheffield) were entered into this study if they survived until discharge from the neonatal unit and were from singleton or twin pregnancies (higher order multiple births were excluded). They came from a larger cohort enrolled in a trial of preterm infant feeding between 1982 and $1984,{ }^{6}$ for whom extensive data had been collected on antenatal factors, delivery, and postnatal events.

Social class of the family was coded using the Registrar General's classification, ${ }^{7}$ social class 3 being subdivided into manual and non-manual. Mother's education was classified in 5 grades: $1=$ no educational qualifications, $2=$ up to four passes for the Certificate of Secondary Education (CSE), $3=$ any $O$ levels or more than four passes for CSE, $4=$ any $A$ levels, and $5=$ degree or higher professional qualification. The child's birth rank in the living children of the family was recorded, with twins being assigned equal rank.

Surviving infants were invited to a follow up appointment at 18 months from expected date of delivery. Infants from the East Anglian centres were seen by RM; RP supervised follow up in Sheffield. A medical and developmental history and extensive physical examination were undertaken. Naked weight, supine length, occipitofrontal head circumference, and triceps and subscapular skinfold thickness were measured. Bayley mental and motor scales were administered, ${ }^{8}$ together with the academic scale of Developmental Profile II. ${ }^{9}$ Scores were calculated using the infants' ages from expected date of delivery. The Bayley mental scale, like most infant tests, requires age-appropriate fine motor skills. It is therefore of limited use in infants with cerebral palsy. The academic scale of Developmental Profile II, a questionnaire based test, depends much 
less on fine motor skills at this age. Mean Bayley mental scores were therefore calculated for neuroogically normal infants, whereas mean Intelligence Quotient (IQ) equivalent (from Developmental Profile II) was calculated for all infants.

Student's $t$ test and the $\chi^{2}$ test were used for univariate statistical analyses except in the case of Apgar score, when the Wilcoxon rank sum test was used. Multiple regression analyses were used to evaluate outcome; linear regression for continuous dependent variables and logistic regression for dichotomous dependent variables.

\section{Results}

Altogether 476 infants, 386 singletons and 90 twins $(19 \%)$, were enrolled in this study. Eight infants (six singletons and two twins) died after leaving the neonatal unit and before the 18 month assessment. The two groups of survivors ( 88 twins compared with 380 singletons) had similar mean (SD) birth weight (1281 (265) g compared with 1277 (291) g) and gestational age $(29.2(1.7)$ weeks compared with $29.2(1.5)$ weeks). Males accounted for $59 \%$ of twins and $49 \%$ of singletons. Seventy two of the twins were from 36 surviving pairs, 16 were from pairs where the other twin had died (four stillborn, 11 neonatal deaths, and one later death).

Table 1 shows those social, obstetric, and neonatal factors that were significantly associated with twins.

Table 1 Social, obstetric, and neonatal factors associated with twins. Results are No (\%) except where otherwise stated

\begin{tabular}{|c|c|c|c|}
\hline & $\begin{array}{l}\text { Twins } \\
(n=88)\end{array}$ & $\begin{array}{l}\text { Singletons } \\
(n=380)\end{array}$ & p Value \\
\hline $\begin{array}{l}\text { Social factors: } \\
\text { No previous living } \\
\text { children }\end{array}$ & $69(78)$ & 191(50) & $<0.001^{*}$ \\
\hline $\begin{array}{l}\text { Obstetric factors: } \\
\text { Primiparous mother } \\
\text { Pregnancy induced } \\
\text { hypertension } \\
\text { Antepartum haemorrhage } \\
\text { Steroids (maternal) } \\
\text { Spontaneous onset of } \\
\text { labour } \\
\text { Caesarean delivery }\end{array}$ & $\begin{array}{c}51(58) \\
4(5) \\
8(9) \\
25(28) \\
\\
74(84) \\
29(33)\end{array}$ & $\begin{array}{r}71(19) \\
102(23) \\
53(14) \\
\\
236(62) \\
181(48)\end{array}$ & $\begin{array}{l}<0.01^{*} \\
<0.05^{*} \\
<0.05^{*} \\
<0.05^{*} \\
<0.01^{*} \\
<0.05^{*}\end{array}$ \\
\hline $\begin{array}{l}\text { Neonatal factors: } \\
\text { Mean (SD) temperature on } \\
\text { admission to special care } \\
\text { baby unit }\left({ }^{\circ} \mathrm{C}\right) \\
>5 \text { Days in over } 30 \% \\
\text { oxygen }\end{array}$ & $36(0 \cdot 7)$ & $35 \cdot 7(0 \cdot 9)$ & $<0.005 \dagger$ \\
\hline
\end{tabular}

${ }^{*}$ By $\chi^{2}$ test; $†$ by $t$ test.
Statistical analysis of maternal factors included mothers of twins once. Other social and obstetric factors found not to be associated with twinning were: mother's age, educational level or marital status, social class, bleeding in the first trimester of pregnancy, and prolonged rupture of membranes or breech delivery. In the neonatal period no significant differences were found between twins and singletons in Apgar score at 5 minutes, the proportion who were small for gestational age, or required mechanical ventilation for more than five days.

Follow up data were collected on $354 / 380(93 \%)$ singletons and $82 / 88(93 \%)$ twins. Table 2 shows the outcome differences between twins and singletons. There were no significant differences in neurodevelopmental status or weight whereas head circumference and triceps and subscapular skinfold thickness were significantly greater in twins and length was significantly less in twins. While the outcome data in table 2 are shown for descriptive purposes, the comparison between twins and singletons is highly confounded. (For instance, the difference in sex ratio (above) would increase the observed difference in length and decrease that for head circumference.)

Regression models were used, therefore, to determine whether there were significant differences between twins and singletons in terms of growth or development at 18 months post-term, after adjusting for possible confounding factors, including sex of infant and all those listed above and in table 1. Stepwise regression was used so that only those factors significantly related to each outcome were included in the final model. After adjusting for these factors, being a twin was not significantly associated

Table 2 Outcome in twins and singletons at 18 months post-term. Results are mean (SE)

\begin{tabular}{|c|c|c|c|}
\hline Outcome measure & $\begin{array}{l}\text { Twins } \\
(n=82)\end{array}$ & $\begin{array}{l}\text { Singletons } \\
(n=354)\end{array}$ & $p$ Value \\
\hline Cerebral palsy & $10 / 82$ & $35 / 354$ & $0 \cdot 48$ \\
\hline $\begin{array}{l}\text { Bayley mental } \\
\text { developmental index* }\end{array}$ & $100 \cdot 8(2 \cdot 2)$ & $101 \cdot 2(1 \cdot 1)$ & $0 \cdot 88$ \\
\hline $\begin{array}{l}\text { Bayley psychomotor } \\
\text { developmental index* }\end{array}$ & $91 \cdot 6(2 \cdot 0)$ & $93.4(0.9)$ & 0.43 \\
\hline IQ equivalent & $105.0(1.9)$ & $105 \cdot 2(0 \cdot 9)$ & 0.89 \\
\hline Weight (kg) & $10 \cdot 1(0 \cdot 2)$ & $10 \cdot 2(0.07)$ & 0.75 \\
\hline Length $(\mathrm{cm})$ & $79.0(0.4)$ & $79.9(0.2)$ & $<0.05$ \\
\hline Head circumference $(\mathrm{cm})$ & $48 \cdot 4(0 \cdot 2)$ & $48.0(0.09)$ & $<0.05$ \\
\hline $\begin{array}{l}\text { Triceps skinfold } \\
\text { thickness }(\mathbf{m m})\end{array}$ & $8.4(0.2)$ & $7 \cdot 9(0 \cdot 1)$ & $<0.05$ \\
\hline $\begin{array}{l}\text { Subscapular skinfold } \\
\text { thickness (mm) }\end{array}$ & $5 \cdot 8(0 \cdot 1)$ & $5.4(0.06)$ & $<0.05$ \\
\hline
\end{tabular}

*Children with cerebral palsy were excluded from these comparisons by $t$ test. 
Table 3 Significant effects of being a twin on anthropometry at 18 months post-term: regression analysis

\begin{tabular}{lll}
\hline Measurement & $\begin{array}{l}\text { Effect of being a twin } \\
(95 \% \text { confidence interval })\end{array}$ & $\begin{array}{l}\text { p Value } \\
\text { of regression } \\
\text { coefficient }\end{array}$ \\
\hline $\begin{array}{l}\text { Length (cm) } \\
\begin{array}{l}\text { Mean skinfold } \\
\text { thickness (mm) }\end{array}\end{array}$ & $-1.59(-0.77$ to -2.41$)$ & $<0.005$ \\
\hline
\end{tabular}

* Mean skinfold thickness is the mean of triceps and subscapular measurements.

with weight or head circumference at 18 months. There was a marginally significant association with triceps skinfold thickness $(p<0.06)$ and significant associations with length $(p<0.005)$, subscapular skinfold thickness $(p<0.05)$, and mean of triceps and subscapular skinfold thickness $(\mathrm{p}<0.03)$ (table $3)$, twins being shorter and fatter than singletons.

Being a twin, rather than singleton, was not significantly associated with the incidence of cerebral palsy, Bayley mental or psychomotor developmental indices (in the neurologically normal infants), or IQ equivalent.

There were 45 first twins and 43 second twins, of whom 41 in each group were seen at 18 months post-term. Second twins were significantly more likely than first to be breech deliveries (1/45 compared with 8/43, p<0.05). Apgar score at 5 minutes was significantly lower for second twins $(p<0 \cdot 02)$. At 18 months post-term there were no significant anthropometric differences between first and second twins. Mean (SD) weight for second twins was $9.9(1.5) \mathrm{kg}$ compared with $10.3(1.4) \mathrm{kg}$ for first, mean length was $78.4(3.4) \mathrm{cm}$ compared with $79.4(3.1) \mathrm{cm}$, and mean head circumference was $48.2(1.4) \mathrm{cm}$ compared with $48.5(1.5) \mathrm{cm}$. There were no significant differences in neurodevelopmental outcome; cerebral palsy was diagnosed in 4/41 first and 6/41 second twins. Mean Bayley mental developmental index was $100 \cdot 5$ $(16 \cdot 7)$ in first twins and 101.1 (19.3) in second.

\section{Discussion}

It is commonly thought that preterm twins have a worse prognosis than preterm singletons. Our study shows, however, that for most factors analysed, this is not the case. Nevertheless, within the population of infants born before 32 weeks' gestation significant differences have emerged between premature twins and singletons. There were significant social, obstetric, and neonatal differences between twins and singletons, shown in table 1 . These differences are broadly similar to those shown in previous studies, ${ }^{10} 11$ though the lower incidence of pregnancy induced toxaemia and greater proportion of primiparae in mothers of preterm twins contrasts with data relating to twin pregnancies of all gestations. $^{12}$

After adjusting for confounding factors, twins were shorter and had thicker subscapular skinfolds than singletons at 18 months' post-term. Silva et al found that twins were shorter, lighter, and had smaller head circumferences than singletons at 3,5 , 7,9 , and 11 years, ${ }^{34}$ although these results could have been explained by the lower mean birth weight and shorter mean gestation in the twin group. We have shown the differences in length and skinfold thickness are still present when preterm twins are compared with preterm singletons and after adjustment for other factors.

The principal observation in this study, however, was that there was no significant differences between preterm twins and singletons in neurodevelopmental outcome, either before or after adjusting for confounding factors. Thus there was no difference in the incidence of cerebral palsy, in Bayley mental or psychomotor indices, of in IQ equivalent. These data contrast with those reported for twins of all gestations inclusive,${ }^{34}$ in whom there was a significant neurodevelopmental disadvantage, but support those of Alberman who found that in children born before 32 weeks' gestation the risk of cerebral palsy was not significantly greater among twins than singletons. ${ }^{13}$

In a comparison of first and second twins it was found that second twins were more likely to be delivered by the breech and had significantly lower Apgar scores at 5 minutes. This did not, however, lead to any significant neurodevelopmental disadvantage at 18 months' post-term. Second twins were generally smaller at this age, but none of the anthropometric differences reached significance:

A gestational age cut off was used for this report because, if we had used the $1850 \mathrm{~g}$ birth weight cut off on which the whole study cohort was based, ${ }^{6}$ only the smaller twin from some pairs would have been included. We were interested to find, however, that when the same analyses were done using the whole cohort under $1850 \mathrm{~g}$ birth weight (596 singletons compared with 156 twins) there were no significant differences in neurodevelopmental outcome, but the twins were again significantly shorter at 18 months' post-term, and had significantly thicker triceps and subscapular skinfolds. We suggest that twins have an intrinsic disadvantage in subsequent linear growth and that the length differences seen in other studies are not entirely due to the lower mean gestation and birth weight of twins. In contrast we did not find evidence of a neuro- 
developmental disadvantage for preterm twins compared with preterm singletons. We suggest that the developmental disadvantage seen for twins in other studies may be due to the increased prevalence of preterm delivery in these infants, and may not reflect an inherent disadvantage for babies from twin pregnancies.

\section{References}

1 Thompson AS, Lyons TL, Makowski CL. Outcomes of twin gestations at the University of Colorado Health Sciences Center 1973-1983. J Repro Med 1987;32:328-39.

2 Gedda L, Benci G, Gatt I. Low birthweight in twins versus singletons: separate entities and different implications for child growth and survival. Acta Genet Med Gemellol 1981;30:1-8.

3 Silva PA, McGree RO, Powell J. The growth and development of twins compared with singletons at ages 5 to 7. Aust Paediatr J 1982;18:35-6.

${ }^{4}$ Silva PA, Crosado B. The growth and development of twins compared with singletons at ages 9 and 11. Aust Paediatr $J$ 1985;21:265-7.

${ }^{5}$ Stanley F. Social and biological determinants of the cerebral palsies. In: Stanley F, Alberman E, eds. The epidemiology of the cerebral palsies. Clinics in developmental medicine No 87.
London: Spastics International Medical Publications, 1984:69-86.

${ }^{6}$ Lucas A, Gore SM, Cole TJ, et al. Multicentre trial on feeding low birthweight infants: effects of diet on early growth. Arch Dis Child 1984;59:722-30.

7 Office of Population Censuses and Surveys. Classification of occupations. London: HMSO, 1980.

${ }^{8}$ Bayley N. Bayley scales of infant development. New York: The Psychological Corporation, 1969.

9 Alpern GD, Boll TJ, Shearer MS. Developmental profile II. Aspen, Colorado: Psychological Developmental Publications, 1980.

${ }^{10}$ MacGillivray I. Maternal complications and twin pregnancy. Eur J Obstet Gynecol Reprod Biol 1983;15:263-8.

1 Buekens P, Lagasse R, Puissant F, Leroy F. Do breech presentations in twins and singletons run different risks? Acta Genet Med Gemellol 1985;34:207-11.

12 McMullen PF, Norman RJ, Marivate M. Pregnancy-induced hypertension in twin pregnancy. Br J Obstet Gynaecol 1984;91: 240-3.

13 Alberman ED. Cerebral palsy in twins. Guys Hospital Reports 1964;113:285-95.

Correspondence to Dr R Morley, Dunn Nutritional Laboratory, Downhams Lane, Milton Road, Cambridge CB4 1XJ.

Accepted 3 January 1989 